\title{
Analiza wczesnych wyników leczenia chorych na czerniaka skóry poddanych biopsji węzła wartowniczego
}

\author{
Wojciech Łobaziewicz, Tomasz Wojewoda, Elżbieta Marczyk, \\ Jerzy Mituś, Wojciech M. Wysocki
}

\begin{abstract}
Wstęp. Chirurgia jest główną metodą leczenia czerniaka skóry. Skuteczność leczenia zależy od zaawansowania nowotworu. Większość czerniaków w Polsce wykrywana jest w stopniu > pT1a, dlatego u tych chorych należy wykonać biopsję węzła wartowniczego (sentinel node biopsy - SNB). Metoda ta w sposób precyzyjny określa zaawansowanie regionalne (węzłowe). Celem pracy była ocena wczesnych wyników leczenia u chorych na czerniaka skóry poddanych SNB.
\end{abstract}

Materiał i metody. W latach 2010-2012 w Klinice Chirurgii Onkologicznej Centrum Onkologii w Krakowie wykonano SNB u 115 chorych na czerniaka skóry (72 kobiety i 43 mężczyzn). Przeprowadzono analizę statystyczną wybranych parametrów wpływających na czas przeżycia bezobjawowego.

Wyniki.U 15 (13\%) chorych stwierdzono przerzuty w SN. Większą grubość czerniaków stwierdzono w grupie, w której SN zawierał przerzut $(5,16$ vs 3,87 mm, $\mathrm{p}=0,08)$. W okresie obserwacji u 23 chorych wystąpił nawrót choroby w postaci odległych przerzutów (17 chorych) lub wznowy lokoregionalnej (6 chorych). W grupie, w której stwierdzono przerzut w SN, do nawrotu doszło u 8 chorych (53\%); w grupie, w której SN nie zawierał przerzutu, nawrót stwierdzono u 15 chorych (15\%). Stwierdzono, że chorzy z nawrotem choroby mieli grubsze czerniaki $(7,1$ vs 3,53 mm, p=0,03). Stwierdzono też znamienną różnicę pod względem przebiegu krzywych przeżycia bez objawów nowotworu (metoda Kaplana-Meiera) dla grupy z przerzutem oraz bez przerzutu w SN. Przeprowadzono analizę niezależnych czynników prognostycznych metodą Coxa. Stan SN oraz aktywność mitotyczna guza były niezależnymi czynnikami istotnie wpływającymi na przeżycia bezobjawowe $(p=0,001)$.

Wnioski. SNB jest efektywną metodą identyfikacji chorych na czerniaka z subklinicznymi przerzutami w regionalnych węzłach chłonnych. Grubość czerniaka określana wg Breslowa jest istotnym czynnikiem ryzyka przerzutów w regionalnych węzłach chłonnych. Obecność przerzutu w SN oraz duża aktywność mitotyczna znamiennie zwiększają ryzyko nawrotu choroby.

\section{Sentinel node biopsy in cutaneous melanoma patients - early results}

Introduction. Surgery is the main treatment option for skin melanoma and the treatment results depend on stage. Most melanomas diagnosed in Poland are > pT1a and therefore sentinel node biopsy (SNB) is needed for accurate allows for accurate regional (nodal) staging. The aim of this work was to assess early treatment results in skin melanoma patients undergoing SNB.

Material and methods. From 2010 to 2012 in the Department of Surgical Oncology, Cancer Center in Kraków, 115 skin melanoma patients underwent SNB (72 females and 43 males). Selected parameters potentially influencing survival were analyzed.

Results. In 15 (13\%) patients SN was positive. In patients with positive SN melanomas were thicker compared to SN negative patients ( 5.16 versus $3.87 \mathrm{~mm}, \mathrm{p}=0.08)$. In 23 patients the disease relapsed: distant metastases $(n=17)$ or locoregional recurrence $(n=6)$. In the group with positive $S N$, recurrence was noted in 8 cases $(53 \%)$; in the group with negative SN, recurrence was seen in 15 patients (15\%). Recurrent patients were characterised by thicker melanomas 
(7.1 versus $3.53 \mathrm{~mm}, \mathrm{p}=0.03$ ). No evidence of disease survival (Kaplan-Meier) curves were significantly separated for positive and negative SN groups. Cox analysis was used for prognostic parameters. SN status and mitotic index were shown to independently influence survival time with no evidence of disease $(p=0.001)$.

Conclusions. SNB effectively identifies melanoma patients with microscopic regional node metastases. Melanoma thickness (Breslow) significantly influences the risk for nodal metastases. Presence of nodal metastasis in SN and high mitotic activity significantly increased the risk of relapse.

NOWOTWORY Journal of Oncology 2014; 64, 5: 391-395

Słowa kluczowe: czerniak skóry, biopsja węzła wartowniczego, czynniki rokownicze, nawrót, przeżycia bezobjawowe Key words: cutaneous melanoma, sentinel node biopsy, prognostic factors, recurrence, no evidence of disease survival

\section{Wstęp}

Czerniak skóry to nowotwór złośliwy, którego główną metodą leczenia jest operacja. Niestety, od lat zachorowalność na czerniaka w Polsce systematycznie wzrasta. $\mathrm{Na}$ podstawie danych epidemiologicznych Centrum Onkologii w Warszawie w 2011 r. rozpoznano w Polsce 2642 nowe zachorowania na czerniaka skóry, co stanowiło około $2 \%$ wszystkich nowo rozpoznanych nowotworów złośliwych [1]. Skuteczność leczenia czerniaka, tak jak większości nowotworów złośliwych, jest pochodną odpowiednio wczesnego rozpoznania. Prowadzone programy edukacyjne (np. aktywność Akademii Czerniaka) powodują wcześniejsze zgłaszanie się chorych do leczenia, co poprawia rokowanie.

Jeżeli w momencie rozpoznania czerniaka nie stwierdza się przerzutów regionalnych (węzłowych) i odległych, a miejscowe zaawansowanie czerniaka przekracza pT1a, to rekomendowanym postępowaniem powinna być biopsja węzła wartowniczego (sentinel node biopsy - SNB) [2, 3]. Niestety, większość czerniaków rozpoznawanych w Polsce ma zaawansowanie miejscowe wyższe niż pT1a (grubość wg Breslowa $>1 \mathrm{~mm}$ lub liczba mitoz $\geq 1 / \mathrm{mm}^{2}$ lub obecne mikroskopowe owrzodzenie guza), dlatego znaczący odsetek chorych, poza miejscowym wycięciem ogniska pierwotnego, wymaga SNB. Wiadomo, że u chorych na czerniaka skóry ocena stanu węzła wartowniczego jest jednym z najsilniejszych czynników prognostycznych [2]. Podsumowanie trwającej 10 lat obserwacji w ramach badania MSLT (Multicenter Selective Lymphadenectomy Trial) wykazało, że SNB poprawia przeżycia bezobjawowe u chorych na czerniaka, natomiast w grupie chorych z przerzutami do węzłów chłonnych u chorych na czerniaki pośredniej grubości SNB poprawia przeżycia wolne od nowotworu oraz wolne od odległych przerzutów [4].

Celem pracy była ocena wczesnych wyników leczenia u chorych na czerniaka skóry poddanych SNB w jednym ośrodku wielodyscyplinarnym.

\section{Materiał i metody}

W latach 2010-2012 w Klinice Chirurgii Onkologicznej Centrum Onkologii w Krakowie wykonano SNB u 115 cho- rych na czerniaka skóry (72 kobiety i 43 mężczyzn). Większość chorych (111) miała wcześniej wyciętą zmianę pierwotną. $U$ pozostałych 4 chorych rozpoznanie postawiono w oparciu o badanie wycinka pobranego z dużej zmiany. Rozkład cechy pT w badanej grupie przedstawia tabela I. Do SNB standardowo kwalifikowano chorych z cechą > pT1a; ponadto $w$ badanej grupie chorych poddanych SNB znalazło się 3 chorych z cechą pT1a, u których biopsję węzła wartowniczego wykonano na jednoznaczne żądanie pacjenta.

Umiejscowienie czerniaka było następujące: kończyny 69 chorych (60\%), tułów - 40 (35\%), głowa i szyja - 6 (5\%). Mała liczba czerniaków umiejscowionych na skórze głowy i szyi wynika z faktu złożonego spływu chłonki tego obszaru [3], co było przyczyną ostrożnego kwalifikowania takich chorych do SNB (w początkowym okresie trwania badania). Średni wiek pacjentów wynosił 60 lat (20-87 lat). Średnia grubość czerniaka — wg klasyfikacji Breslowa - wyniosła $4 \mathrm{~mm}$ (mediana $3 \mathrm{~mm}$ ). Wszystkich chorych - w celu oceny zaawansowania - poddawano szczegółowemu badaniu klinicznemu, badaniom biochemicznym z krwi oraz badaniom obrazowym (USG regionalnych grup węzłów chłonnych, RTG klatki piersiowej i USG jamy brzusznej).

Po wykluczeniu za pomocą oceny klinicznej obecność regionalnych i odległych przerzutów oraz uzyskaniu pisemnej świadomej zgody, chorych kwalifikowano do SNB. Procedurę wykonywano, podając śródskórnie izotop technetu ( ${ }^{99 \mathrm{~m} T \mathrm{~T})}$ związany z albuminą, około 2 godziny przed operacją. Wykonywano dwa wkłucia w odległości ok. $1 \mathrm{~cm}$ po obu stronach blizny po wyciętej zmianie pierwotnej, następnie wykonywano limfoscyntygrafię oraz badanie SPECT/CT. Około 15 minut przed zabiegiem podawano błękitny barwnik (Patentblau). Zabiegi u większości chorych wykonywano w znieczuleniu ogólnym. SN lokalizowano za pomocą ręcznej sondy gamma (Gamma Finder) w korelacji z wynikami limfoscyntygrafii. U wszystkich chorych z powodzeniem zlokalizowano SN. Mediana liczby wyciętych SN wyniosła 2. Pacjentów wypisywano do domu dzień po zabiegu.

Po przebytym leczeniu chorzy byli regularnie kontrolowani w Centrum Onkologii w Krakowie. W pierwszych dwóch latach kontrole wykonywano w odstępach trzymie- 
Tabela I. Charakterystyka badanej grupy chorych

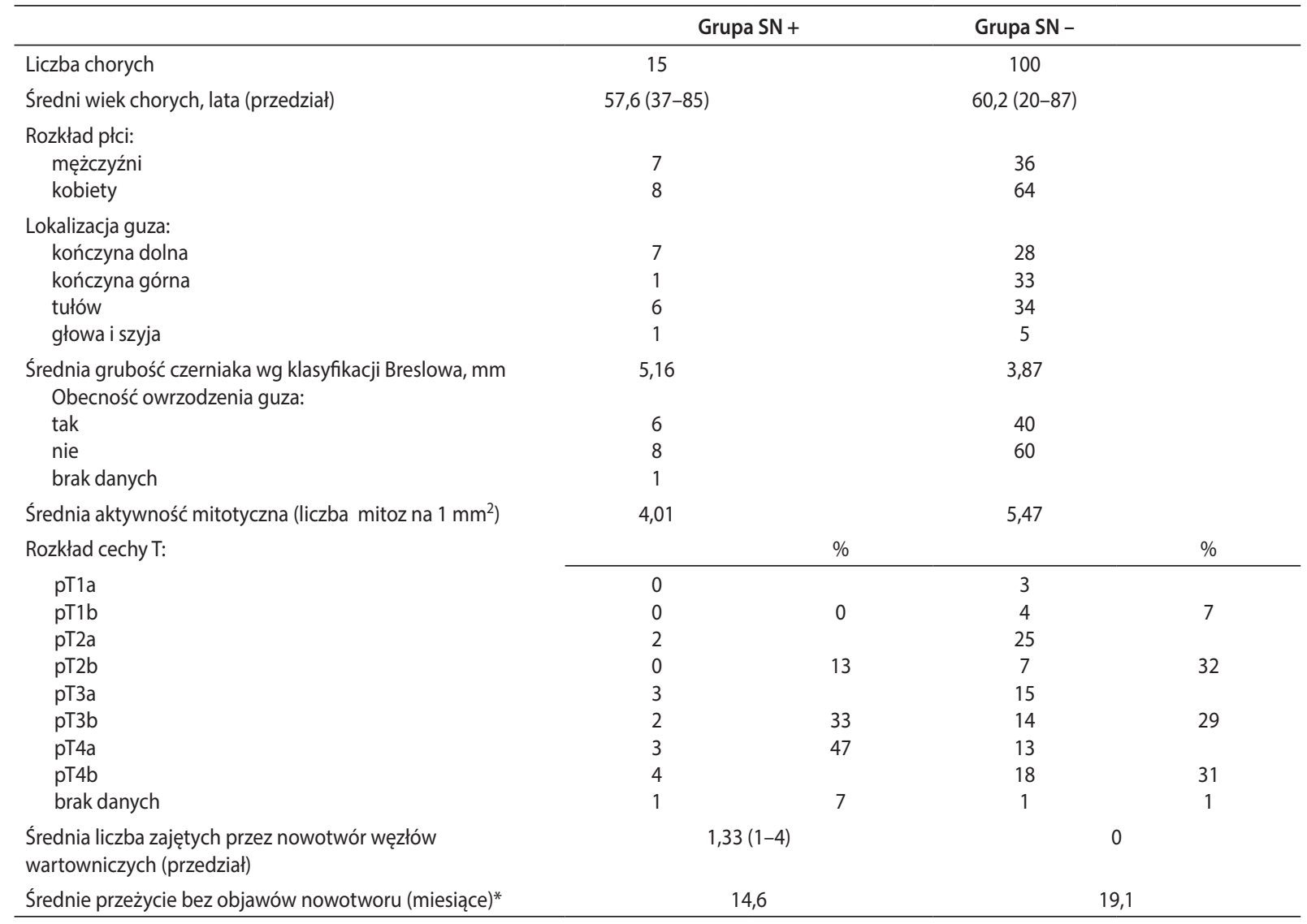

*okres obserwacji wyniósł średnio 22,3 miesiąca

sięcznych, a następnie - co 6 miesięcy. Standardowo kontrole obejmowały wywiad oraz badanie kliniczne, ponadto raz w roku wykonywano prześwietlenie klatki piersiowej, USG jamy brzusznej oraz regionalnych węzłów chłonnych. W razie podejrzenia nawrotu choroby wykonywano odpowiednie badania dodatkowe.

\section{Wyniki}

U 15 (13\%) chorych stwierdzono przerzuty czerniaka w wyciętym węźle wartowniczym. W tej grupie u 13 chorych usunięto odpowiednią grupę węzłów chłonnych (uzupełniająca limfadenektomia); 2 pozostałych chorych odmówiło zgody na dodatkową operację. Przerzuty w węzłach „niewartowniczych" po wykonanej limfadenektomii stwierdzono u 2 chorych (15\%).

Średnia długość obserwacji od SNB wyniosła w badanej grupie 22,3 miesiąca (2-42 miesięcy). Biorąc pod uwagę, że większość chorych poddano SNB w okresie do 2 miesięcy po wycięciu zmiany pierwotnej, można przyjąć, że średnia długość obserwacji od wycięcia zmiany pierwotnej wynosiła 2 lata. Jest to istotne, ponieważ większość nawrotów w tej grupie chorych występuje w ciągu dwóch lat [3-5].

U 23 chorych wystąpił nawrót choroby w postaci odległych przerzutów (17 chorych) lub wznowy lokoregionalnej
(6 chorych). W grupie, w której stwierdzono przerzut w wyciętym węźle wartowniczym, do nawrotu doszło u 8 chorych (53\%); w grupie, w której węzeł wartowniczy nie zawierał przerzutu, nawrót stwierdzono u 15 chorych (15\%). Nawrót w regionalnej grupie węzłów chłonnych wśród pacjentów, u których wynik badania wyciętego węzła wartowniczego nie ujawnił przerzutu, stwierdzono tylko u 1 chorego (1\%). Stwierdzono, że chorzy z nawrotem choroby mieli grubsze czerniaki $(7,1$ vs 3,53 mm, p=0,03). Większą grubość czerniaków stwierdzono w grupie, w której węzeł wartowniczy zawierał przerzut $(5,16$ vs 3,87 $\mathrm{mm}, \mathrm{p}=0,08)$.

Wykonano analizę czasu przeżycia bez objawów nowotworu (no evidence of disease) dla obu grup (ryc. 1) metodą Kaplana-Meiera. Krzywe porównano testem LR (likelihood ratio test), stwierdzając znamienną różnicę: czas przeżycia bezobjawowego w grupie bez przerzutu w wartowniczym węźle chłonnym był dłuższy niż w grupie, w której stwierdzono przerzut w wartowniczym węźle chłonnym ( $p=0,001$; ryc. 1 ).

Następnie wykonano analizę niezależnych czynników prognostycznych metodą Coxa. Metodą regresji krokowej wybrano model najlepiej opisujący przeżycia bezobjawowe (tab. II). Do modelu weszły dwie zmienne: 1) SN $[H R=7,807$ oznacza, że pacjenci z SN+ mają w każdym czasie niemal 8 razy większe ryzyko nawrotu niż pacjenci 


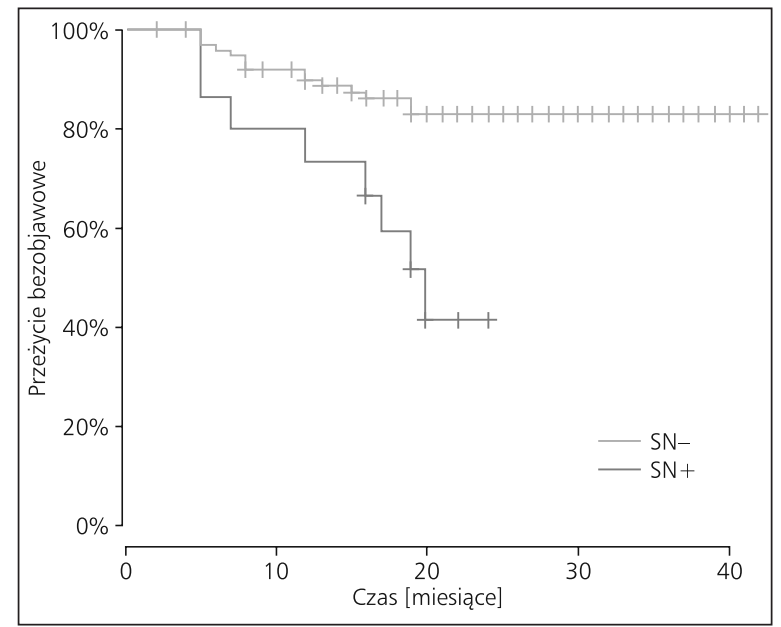

Rycina 1. Krzywe przeżycia bezobjawowego wyznaczone metoda Kaplana-Meiera (pionowe kreski oznaczają obserwacje ucięte; $p=0,001$ )

z SN-] oraz 2) aktywność mitotyczna [HR = 1,092 oznacza, że wzrost aktywności o jedną jednostkę podnosi ryzyko nawrotu w każdym czasie o 9,2\%]. Zmienne, które nie osiągnęły istotności statystycznej w badanym modelu, to grubość nacieku wg klasyfikacji Breslowa, płeć, wiek oraz obecność owrzodzenia.

\section{Dyskusja}

SNB jest uznaną metodą identyfikacji niemych kliniczne przerzutów (mikroprzerzutów) do regionalnych węzłów chłonnych u chorych na czerniaka skóry. U około $20 \%$ chorych na niezaawansowanego czerniaka stwierdza się przerzuty w wyciętych wartowniczych węzłach chłonnych [3, 6-8]. Odsetek ten w naszej grupie wyniósł 13\%. Skuteczność identyfikacji węzłów wartowniczych przekracza 98-99\% [9]; w analizowanej grupie u wszystkich chorych udało się zidentyfikować węzeł wartowniczy. W ośrodkach dysponujących odpowiednim doświadczeniem fałszywie ujemna identyfikacja węzła wartowniczego jest bardzo rzadka. Standardowym postępowaniem w przypadku obecności przerzutu w wartowniczym węźle chłonnym jest uzupełniająca limfadenektomia. W analizowanej grupie 2 chorych nie wyraziło zgody na takie postępowanie pomimo przerzutu w wartowniczym węźle chłonnym. Przerzut w,niewartowniczym” węźle stwierdzono u 2 chorych (15\%). Gyorki i wsp. w analizie dotyczącej czerniaków skóry obszaru głowy i szyi stwierdzili przerzuty w węzłach niewartowniczych u $22 \%$ chorych [3], natomiast w przypadku innych lokalizacji ogniska pierwotnego zjawisko to dotyczyło od 8 do $33 \%$ chorych [7].

Czas bezobjawowego przeżycia w grupie chorych bez przerzutu w wartowniczym węźle chłonnym był znamiennie dłuższy w porównaniu z drugą grupą $(p=0,001)$. Silnym czynnikiem rokowniczym dla nawrotu czerniaka jest stan węzła wartowniczego - w naszej grupie nawrót dotknął 53\% chorych, u których węzeł wartowniczy zawierał przerzut - w porównaniu z 15\% chorych bez przerzutu w tym węźle. Odsetki te są zbliżone do raportowanych w piśmiennictwie [5], a wiele analiz potwierdzało, że stan regionalnych węzłów chłonnych u chorych na czerniaka skóry jest najsilniejszym czynnikiem prognostycznym $[4,7,9]$.

Ryzyko nawrotu choroby zależy od wielkości ogniska przerzutu w węźle, jak i od liczby zmienionych przerzutowo węzłów chłonnych [10,11]. W naszej analizie nie ocenialiśmy rokowniczej roli wielkości ogniska przerzutu (zbyt mała grupa), ale potwierdziliśmy, że większa grubość czerniaka zwiększała ryzyko obecności przerzutu w wartowniczym węźle chłonnym $(p=0,08)$, a to z kolei wiązało się z istotnie statystycznie większym ryzykiem nawrotu $(p=0,03)$. Rughani i wsp. w badaniu, które objęło 136 chorych na grube czerniaki (Breslow $\geq 4,0 \mathrm{~mm}$ ), wskazali na istotną różnicę pod względem prawdopodobieństwa przeżycia bez nawrotu choroby pomiędzy chorymi bez przerzutu w SN a chorymi z przerzutem w SN (odsetek 5-letnich przeżyć bez nawrotu czerniaka wynosił odpowiednio 66\% i 27\%) [12].

W skonstruowanym przez nas modelu wykazano, że najsilniej na niepowodzenie leczenia wpływał przerzut w wartowniczym węźle chłonnym (ryzyko nawrotu było w takim przypadku 8 razy większe) oraz aktywność mitotyczna (wzrost aktywności mitotycznej o 1 mitozę na $1 \mathrm{~mm}^{2}$ wiązał się ze zwiększeniem ryzyka nawrotu czerniaka o blisko 10\%). Rolę tych dwóch czynników rokowniczych potwierdza bieżąca rewizja klasyfikacji TNM $[13,14]$. Aktywność mitotyczna guza jużod kilku dekad jest uważana za silny czynnik prognostyczny czerniaka skóry [15, 16]. Dotychczas problemem w porównywaniu różnych grup chorych był niewystandaryzowany sposób pomiaru aktywności mitotycznej czerniaka. Obecnie ustalono, że raport patologiczny powinien określać aktywność mitotyczną guza w przeliczeniu na $1 \mathrm{~mm}^{2}$ [14]. Thompson i wsp. wykazali, że aktywność mitotyczna czerniaka jest drugim (po grubości wg klasyfikacji Breslowa) pod względem znaczenia czynnikiem rokowniczym. Stwierdzono także, że aktywność mitotyczna jest większa w grubszych i owrzodzonych czerniakach [17].

Tabela II. Niezależne zmienne wpływające na przeżycia bez objawów czerniaka — wieloczynnikowy model Coxa

\begin{tabular}{lcccc}
\hline Zmienna & HR & 95\% przedział ufności dla HR & p & \\
\hline SN + & 7,807 & 2,32 & 26,268 & 0,001 \\
Aktywność mitotyczna & 1,092 & 1,037 & 1,15 & 0,001 \\
\hline
\end{tabular}

Uwaga: w wieloczynnikowym modelu Coxa istotności statystycznej nie osiągnęły: grubość nacieku wg klasyfikacji Breslowa, płeć, wiek oraz obecność owrzodzenia 
Brak potwierdzenia rokowniczej roli w odniesieniu do przeżyć bezobjawowych takich zmiennych jak grubość czerniaka wg klasyfikacji Breslowa i obecność owrzodzenia guza w naszym badaniu najprawdopodobniej wynikała z małej liczebności grupy. Ponadto spójność sposobu pomiaru grubości czerniaka wg klasyfikacji Breslowa w naszym materiale może budzić wątpliwości, ponieważ zdecydowana większość chorych była pierwotnie poddana operacji poza naszym ośrodkiem (np. u jednego chorego raportowana grubość wyniosła $4 \mathrm{~cm}$ ). Brak rekonsutlacji preparatu histopatologicznego z zabiegu pierwotnego należy uznać za słabość metodologiczną niniejszej pracy, jednak z drugiej strony trzeba podkreślić, że analizowaną populację tworzy niewyselekcjonowana, rzeczywista grupa chorych z praktyki klinicznej ośrodka onkologicznego. To z kolei zwiększa praktyczną wagę wniosków w warunkach lokalnych.

Wynik oceny wartowniczego węzła chłonnego jest jednym z najsilniejszych czynników prognostycznych u chorych na czerniaka skóry [4, 7]. Ryzyko obecności zmian przerzutowych w SN rośnie wraz z grubością czerniaka, co potwierdzono także w materiale własnym. Identyfikacja chorych z subklinicznymi przerzutami w węzłach chłonnych selekcjonuje chorych do uzupełniającej limfadenektomii. Być może wraz z wprowadzaniem nowych leków sam wynik oceny wartowniczego węzła chłonnego będzie wystarczającym kryterium do kwalifikacji chorych do celowanego leczenia farmakologicznego z pominięciem etapu uzupełniającej limfadenektomii; pominięcie tego etapu jest tym bardziej prawdopodobne, że już pojawiają się wstępne dane wskazujące na możliwość rezygnacji z uzupełniającej limfadenektomii pomimo potwierdzenia przerzutu czerniaka w wartowniczym węźle chłonnym [18].

\section{Wnioski}

Własne analizy potwierdziły, że SNB jest efektywną metodą identyfikacji chorych na czerniaka z subklinicznymi przerzutami w regionalnych węzłach chłonnych. Ponadto potwierdziliśmy, że grubość czerniaka określana wg Breslowa jest istotnym czynnikiem ryzyka przerzutów w regionalnych węzłach chłonnych. Wykazaliśmy, że obecność przerzutu w wartowniczym węźle chłonnym oraz duża aktywność mitotyczna znamienne zwiększają ryzyko nawrotu choroby - przerzut w węźle wartowniczym zwiększa to ryzyko 8-krotnie, zaś każda dodatkowa mitoza na $1 \mathrm{~mm}^{2}$ zwiększa ryzyko o $10 \%$.

Konflikt interesów: nie zgłoszono

\section{Dr med. Wojciech M. Wysocki}

Klinika Chirurgii Onkologicznej

Centrum Onkologii Oddział w Krakowie

ul. Garncarska 11, 31-115 Kraków

tel. 124224928

e-mail:z5wysock@cyf-kr.edu.pl

Otrzymano: 25 czerwca 2014 r

Przyjęto do druku: 30 września 2014 r.

\section{Piśmiennictwo}

1. Krajowy Rejestr Nowotworów. www.onkologia.org.pl

2. Dummer R, Hauschild A, Guggenheim M i wsp. Cutaneous melanoma: ESMO Clinical Practice Guidelines for diagnosis, treatment and follow-up. Ann Oncol 2012; 23 Suppl. 7: vii 86-91.

3. Gyorki DE, Boyle JO, Ganly I i wsp. Incidence and location of positive nonsentinel lymph nodes in head and neck melanoma. Eur J Surg Oncol 2014; 40: 305-310.

4. Morton DL, Thompson JF, Cochran AJ i wsp.. Final trial report of sentinel-node biopsy versus nodal observation in melanoma. $N$ Engl Med 2014; 370: 599-609.

5. Richtig E, Komericki P, Trapp M i wsp. Ratio of marked and excised sentinel lymph nodes and scintigraphic appearance time in melanoma patients with negative sentinel lymph node. Eur J Surg Oncol 2010; 36: 783-788.

6. Murali R, Scolyer RA, Thompson JF. Completion lymph node dissection in melanoma patients with positive sentinel lymph nodes. Eur J Surg Oncol 2013; 39: 1164-1165.

7. Wevers KP, Murali R, Bastiaannet E i wsp. Assessment of a new scoring system for predicting non-sentinel node positivity in sentine node-positive melanoma patients. Eur J Surg Oncol 2013; 39: 179-184.

8. Pasquali S, Mocellin S, Campana LG i wsp. Maximizing the clinical usefulness of a nomogram to select patients candidate to sentinel node biopsy for cutaneous melanoma. Eur J Surg Oncol 2011; 37: 675-680.

9. Vitali GC, Trifirò G, Zonta M i wsp. Lymphoscintigraphy in clinical routine practice: reproducibility and accuracy in melanoma patients with a long-term follow-up. Eur J Surg Oncol 2014; 40: 55-60.

10. Zdzienicki M, Rutkowski P, Nowecki Zl i wsp. The analysis of the outcomes and factors related to iliac-obturator involvement in cutaneous melanoma patients after lymph node dissection due to positive sentinel lymph node biopsy or clinically detected inguinal metastases. Eur J Surg Oncol 2013: 39: 304-310.

11. Balch CM, Gershenwald JE, Soong SJ i wsp.. Multivariate analysis of prognostic factors among 2,313 patients with stage III melanoma: comparison of nodal micrometastases versus macrometastases. J Clin Oncol 2010; 28: 2452-2459.

12. Rughani MG, Swan MC, Adams TS i wsp. Sentinel node status predicts survival in thick melanomas: the Oxford perspective. Eur J Surg Oncol 2012; 38: 936-942.

13. Balch CM, Gershenwald JE, Soong SJ i wsp. Final version of 2009 AJCC melanoma staging and classification. J Clin Oncol 2009; 27: 6199-6206.

14. Wysocka J, Komorowski AL, Wysocki WM i wsp. Czerniak skóry — nowa klasyfikacja TNM (2010). Medycyna Praktyczna — Onkologia 2010; 6: 65-69.

15. Azzola MF, Shaw HM, Thompson JF i wsp. Tumor mitotic rate is a more powerful prognostic indicator than ulceration in patients with primary cutaneous melanoma: an analysis of 3661 patients from a single center. Cancer 2003; 97: 1488-1498.

16. Karjalainen JM, Eskelinen MJ, Nordling Si wsp. Mitotic rate and S-phase fraction as prognostic factors in stage I cutaneous malignant melanoma. Br J Cancer 1998; 77: 1917-1925.

17. Thompson JF, Soong SJ, Balch CM i wsp. Prognostic significance of mitotic rate in localized primary cutaneous melanoma: an analysis of patients in the multi-institutional American Joint Committee on Cancer melanoma staging database. J Clin Oncol 2011; 29: 2199-2205.

18. Nagaraja, V. and Eslick, G.D. Is complete lymph node dissection after a positive sentinel lymph node biopsy for cutaneous melanoma always necessary? A meta-analysis. Eur J Surg Oncol 2013; 39: 269-280. 